\title{
ANKLE
}

\section{Long-term outcomes of muscle volume and Achilles tendon length after Achilles tendon ruptures}

\author{
Claudio Rosso • Patrick Vavken · Caroline Polzer • \\ Daniel M. Buckland · Ueli Studler · Lukas Weisskopf • \\ Marc Lottenbach • Andreas Marc Müller • Victor Valderrabano
}

Received: 6 August 2012/ Accepted: 14 January 2013/Published online: 31 January 2013

(C) Springer-Verlag Berlin Heidelberg 2013

\begin{abstract}
Purpose The best treatment for Achilles tendon (AT) ruptures remains controversial. Long-term follow-up with radiological and clinical measurements is needed.

Methods In this retrospective multicentre cohort study, patients $(n=52)$ were assessed at a mean of 91 months follow-up after unilateral AT rupture treated by open, percutaneous or conservative (non-surgical) treatment. Demographic parameters, time off work, maximum calf circumference and clinical scores (ATRS, Hannover, AOFAS) were evaluated. Muscle volume and cross-sectional area of the calf and AT length were measured on MR images and were compared between groups and to each patient's healthy contralateral leg. Results Reduced muscle volume was found across all groups with a higher muscle volume in the conservative $\left(729.9 \pm 130.3 \mathrm{~cm}^{3}\right)$ compared to the percutaneous group
\end{abstract}

C. Rosso $(\bowtie) \cdot$ P. Vavken · C. Polzer · D. M. Buckland ·

A. M. Müller · V. Valderrabano

Orthopaedic Department, University Hospital Basel

and University of Basel, Spitalstrasse 21,

4031 Basel, Switzerland

e-mail: Claudio.Rosso@unibas.ch

C. Polzer

e-mail: Caroline.Polzer@unibas.ch

A. M. Müller

e-mail: A.Mueller@usb.ch

V. Valderrabano

e-mail: Victor.Valderrabano@usb.ch

P. Vavken

Harvard School of Public Health, Boston, MA, USA

P. Vavken

Children's Hospital Boston, Harvard Medical School,

Boston, MA, USA

e-mail: Patrick.vavken@childrens.harvard.edu $\left(675.9 \pm 207.4 \mathrm{~cm}^{3}, p=0.04\right)$. AT length was longer in the affected leg $(198.4 \pm 24.1$ vs. $180.6 \pm 25.0 \mathrm{~mm}$, $p<0.0001$ ) without difference in subgroup analysis. Clinically measured ankle dorsiflexion showed poor correlation with AT length $\left(R^{2}=0.07, p=0.008\right)$. Muscle volume strongly correlated with the cross-sectional area $\left(R^{2}=0.6\right.$, $p<0.0001)$ but showed a weak correlation with the Hannover score $\left(R^{2}=0.08, p=0.048\right)$. Maximum calf circumference correlated with muscle volume $\left(R^{2}=0.42, p<0.0001\right)$.

Conclusions No significant difference between the treatment groups was found in muscle volume, AT length, clinical measures or days off work. Cross-sectional area and maximum calf circumference are cost-effective measurements and a good approximation of muscle volume and can thus be used in a clinical setting while clinical dorsiflexion should not be used. Level of evidence III.

D. M. Buckland

Center for Advanced Orthopaedic Studies, Beth Israel Deaconess

Medical Center, Harvard Medical School, Boston, MA, USA

e-mail: Dan.Buckland@usb.ch; dbucklan@bidmc.harvard.edu

\section{U. Studler}

Department of Radiology, University Hospital Basel,

University of Basel, Basel, Switzerland

e-mail: Ueli.Studler@usb.ch

L. Weisskopf

Rennbahn Clinic, Muttenz, Switzerland

e-mail: weisskopf@ rennbahnklinik.ch

M. Lottenbach

Cantons Hospital Fribourg, Fribourg, Switzerland

e-mail: lottenbachm@h-fr.ch 
Keywords Calf muscle volume - Cross-sectional area . Achilles tendon length $\cdot$ Achilles tendon rupture

\section{Introduction}

Achilles tendon ruptures are common in sports medicine and their incidence is increasing [1, 14]. Long-term sequelae of Achilles tendon ruptures can be grave: the injured athlete has to rest, and consequences such as therapy, rehabilitation costs and absence from work pose a substantial socio-economic cost. Thus, it is of pivotal importance, both on the individual and societal level, to identify those therapies with the best outcomes [28].

A common long-term problem in Achilles tendon rupture reconstruction, with substantial influence on overall outcome, has been muscle atrophy [13, 25]. A number of studies emphasized the problem of muscle atrophy and its functional implications on ligament and tendon repair, such as poor outcomes and increased risk of re-tears [2, 22, 32, 35]. About the ankle joint, Valderrabano et al. [35] showed muscle atrophy after reconstruction of posterior tibial tendon rupture. Gladstone et al. [4] and Liem et al. [15] showed that muscle atrophy and fatty infiltration are not reversed by successful tendon repair and play a significant role in determining functional outcome. Thus, it is important to assess muscle atrophy and fatty infiltration of the triceps surae after Achilles tendon rupture treatments.

Experts agree that in active patients, surgical treatment of acute Achilles tendon ruptures is superior to non-operative treatment because it allowed an anatomical reconstruction $[1,17,20,26,29,36]$. However, to date, there is still lack of long-term data concerning muscle atrophy-both in volume and cross-sectional area-and fatty infiltration after different types of Achilles tendon rupture treatment, and it is unclear how such tissue degeneration would affect muscle force and clinical outcomes.

It was therefore the primary objective of this study to systematically assess muscle atrophy across the three treatment groups (open repair, percutaneous repair or conservative treatment) in a retrospective, assessor-blind, multicentre study at a minimum follow-up of 3 years. The second objective of this study was to test for an association between Achilles tendon length, muscular degeneration and clinical outcomes, including subgroup analyses by type of treatment (open, percutaneous, conservative). It was hypothesized that open surgery would perform best by means of muscle atrophy and fatty infiltration across the three treatment groups and that there was a significant negative association between muscle atrophy and fatty infiltration and clinical outcomes. It was also hypothesized that conservative treatment yields excessive Achilles tendons length after healing and that generally Achilles tendon cannot be restored to their original length, independent of treatment type.

\section{Materials and methods}

This study was designed as a retrospective, assessor-blinded, multicentre cohort trial with consecutive patients. An IRB approval was granted for this study by the local institutional review board.

Fifty-two patients (females, 11 and males, 41) were recruited from three orthopaedic centres. Demographic data are shown in Fig. 1.

Patients post-unilateral Achilles tendon rupture were contacted a minimum of 3 years after the injury. Further inclusion criteria were: 20-65 years of age, a healthy contralateral leg with physiological, clinically determined alignment of the knee, foot and ankle, no trauma to the healthy leg, no neuromuscular impairments including muscle dystrophies, no other post-traumatic injuries or osteoarthritis of the knee, foot or ankle of the affected leg.

Exclusion criteria were: re-rupture or re-operation of the Achilles tendon, surgical site infection, neuromuscular diseases including muscle dystrophies, ankle valgus of more than $15^{\circ}$ or ankle varus of more than $5^{\circ}$, other known pathologies of the non-affected leg, general MRI exclusion criteria (e.g. pacemaker, other metal not qualifying for an MRI, tattoos and claustrophobia) and a body mass index (BMI) of $>40 \mathrm{~kg} / \mathrm{m}^{2}$. Conservatively treated patients were all recruited from one of the study centres.

The post-treatment (operative or conservative) regimens were identical in all study centres. Treatment was early functional rehabilitation in a stability boot and a night splint. After operative treatment or diagnosis (conservative), patients were allowed partial weight bearing for 2 weeks in $20^{\circ}$ plantar flexion. For weeks 3 and 4, patients were allowed full weight bearing with $20^{\circ}$ of plantar flexion and at week 5 and 6 , patients were reduced to a $10^{\circ}$ plantar flexing heel pad.

\section{Demographic data and clinical assessment}

The type of surgery was noted: open surgery, conservative treatment and percutaneous surgery which consisted of mini-open Kakiuchi [7] repairs, Ma and Griffith [16] repairs and repairs using the Achillon ${ }^{\circledR}$ device. The following clinical patient parameters were noted in a clinical assessment of an orthopaedic surgeon (C.R.): gender, age, body height, weight, BMI and activity level according to the Valderrabano sports score (VSS) [35]. Additionally, time off work, maximum calf circumference, thigh circumference 10 and $20 \mathrm{~cm}$ above the proximal patella apex, ankle dorsiflexion, SF-36 quality of life, proportion 
Fig. 1 Study design. This flow chart depicts patient acquisition at the three hospitals, the number of exclusions as well as the pathway of examinations and analyses. USB University Hospital Basel, KSLI Canton's Hospital Liestal, HFR Canton's Hospital Fribourg. All centres are situated in Switzerland

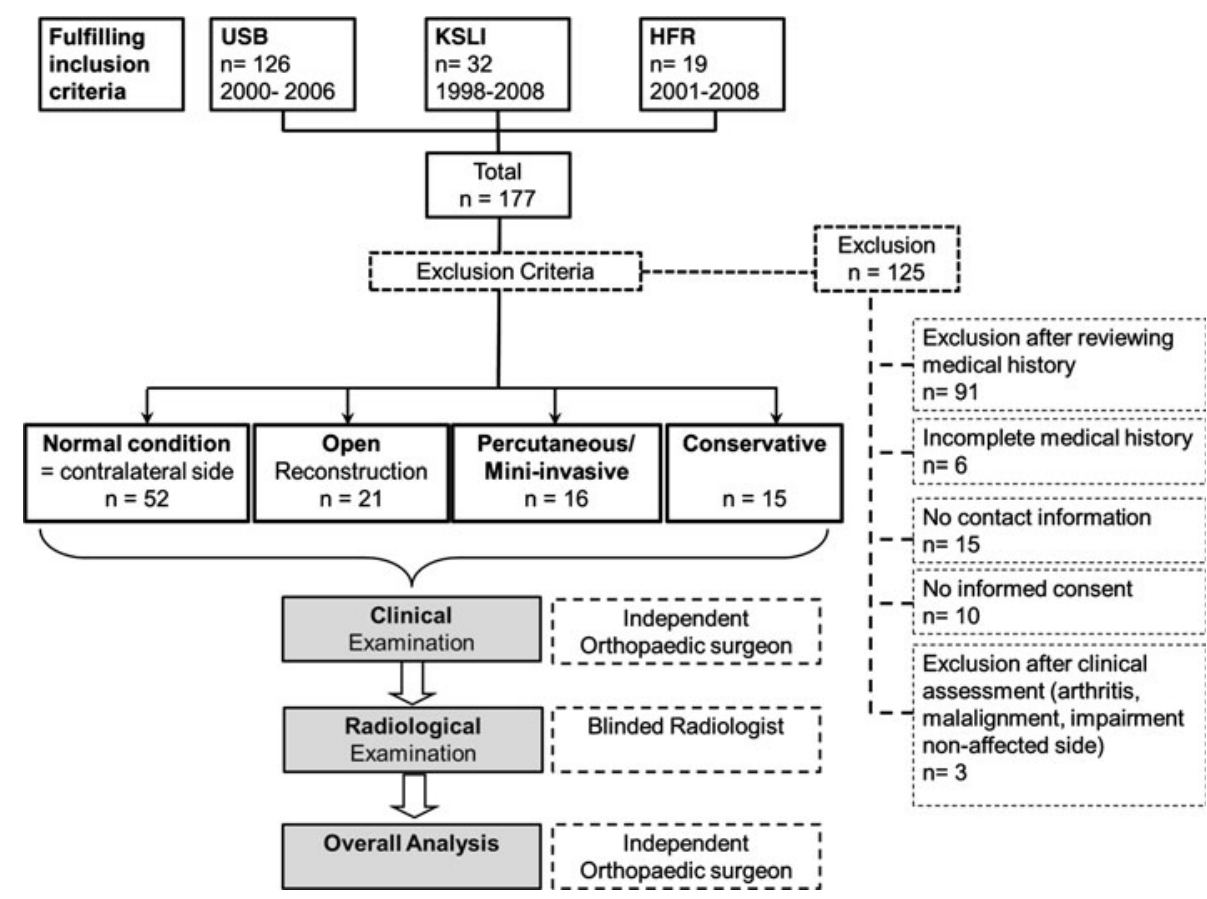

of disabled pensions, Achilles tendon rupture score (ATRS, max. 100 points) [23], Hannover score (max. 100 points) [33] and the AOFAS Hindfoot score (max. 100 points) [11], and adherence of the tendon to the skin were evaluated.

Twenty-one patients were treated with open repair (OPEN), 16 with percutaneous/mini-open repair (PRCT) and 15 with conservative treatment (CONS). The mean follow-up was $91.0 \pm 31.3$ (mean $\pm \mathrm{SD}$ ) months. Both sides were ruptured equally often ( $n=26$ in both groups). There was no significant difference in the average followup duration between the different treatment groups. Mean age at follow-up was $48.6 \pm 8.7$ years (range 23-55) with $49.9 \pm 6.5$ years in females and $48.2 \pm 9.3$ years in males (n.s.) without any significant difference between the groups. The mean body height was $176.8 \pm 8.8 \mathrm{~cm}$ (range 157-196) with $166.5 \pm 5.8 \mathrm{~cm}$ in females and $179.6 \pm 7.2 \mathrm{~cm}$ in males $(p<0.0001)$ but equally distributed among the treatment groups. The mean BMI was $26.2 \pm 3.9 \mathrm{~kg} / \mathrm{m}^{2}$ (range 19.7-39.4) with $25.7 \pm 6.3 \mathrm{~kg} / \mathrm{m}^{2}$ in females and $26.4 \pm 3.0 \mathrm{~kg} / \mathrm{m}^{2}$ in males (n.s.) and similar in all treatment groups. The SF-36 scores were similar in all groups (Fig. 2).

\section{MRI assessment}

MRI assessment was performed on both, the affected leg and the healthy contralateral leg, which served as a normal, matched control.

Imaging was carried out on a 3-TESLA scanner (MAGNETOM Verio, Siemens Medical Solution,

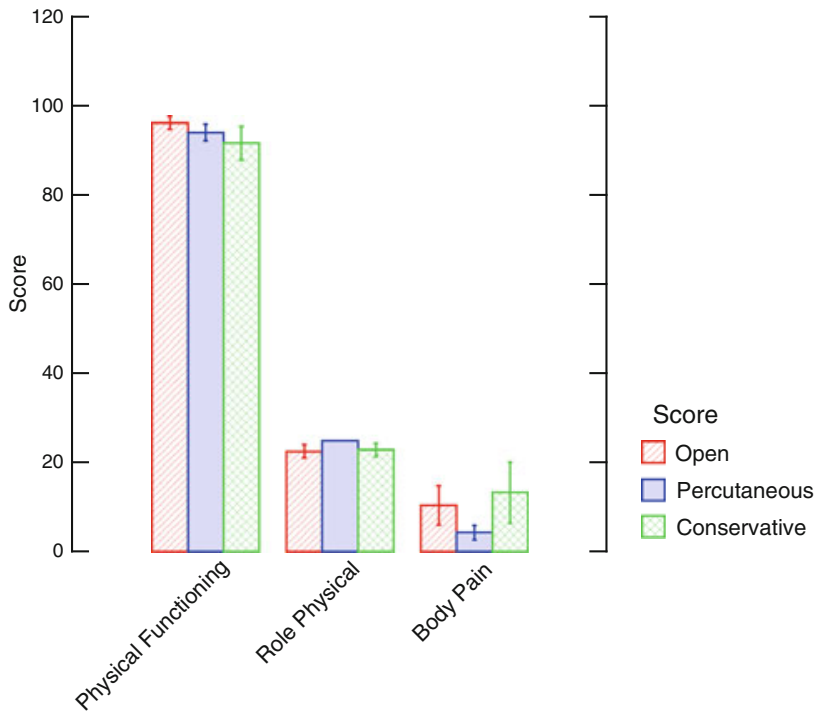

Fig. 2 SF-36 measures across treatment groups. The groups were not significantly different from one another. The box "population average" marks the line of the average score across the population. Selected measures from SF-36, short form 36; no significant differences in any measures were found

Erlangen, Germany). Patients were examined in the supine position with the ankle dorsiflexed at $90^{\circ}$ (flexion neutral position) and the knee in $0^{\circ}$ flexion and fixed in that position with straps and sandbags to assure reliable side comparability. A peripheral angiography matrix coil with 16 coil elements was used for image acquisition. Three sequences were acquired. First, a single-slab T1-weighted, 
magnetization-prepared, rapid acquisition gradient-echo (MPRAGE) sequence (repetition time msec/echo time msec, $1,890 / 3.37$; inversion time msec, 1,000 ; isotropic resolution, $1 \times 1 \times 1 \mathrm{~mm}$ ) was obtained in the coronal plane. The MPRAGE protocol was used to cover the entire lower leg from above the femoral condyles (origin of gastrocnemius muscles) through the bottom of the calcaneus allowing a 3D reconstruction with slices of $1 \mathrm{~mm}$. The accuracy of those measurements was thus $0.1 \mathrm{~cm}$. Second, axial T2-weighted fat-saturated fast spin-echo images $(5,000 / 76$; echo train length, 14; number of signals acquired, 1 ; section thickness, $3 \mathrm{~mm}$; intersection gap, $0 \mathrm{~mm}$; matrix size, $212 \times 512 \mathrm{~mm}$; field of view, $168 \times 400 \mathrm{~mm}$ ) were acquired of both legs simultaneously from the musculotendinous junction to the calcaneal insertion of the Achilles tendon. Third, axial T1weighted fast spin-echo images (725/17; echo train length, 2; number of signals acquired, 1; section thickness, $6 \mathrm{~mm}$; intersection gap, $4 \mathrm{~mm}$; matrix size, $384 \times 384$; field of view, $200 \times 200 \mathrm{~mm}$ ) were performed separately for both legs resulting in approximately 65 slices per leg. Axial T1weighted imaging covered the area from above the origin site of the gastrocnemius muscles (femoral condyles) to the calcaneus.

Quantitative and qualitative radiological measurements were noted. Muscle volume (MV) and cross-sectional area (CSA) were measured in the T1-weighted spin-echo images. Both parameters were measured on each calf muscle separately (soleus muscle (SOL), gastrocnemius medialis (GM) and lateralis (GL) muscles). The area of every muscle was measured on each slice from the distal appearance to the femoral condyles and multiplied by $1 \mathrm{~cm}(6 \mathrm{~mm}$ section thickness and $4 \mathrm{~mm}$ intersection gap) resulting in a close approximation of the MV (Fig. 3). Cross-sectional area was measured at a defined point at the junction of the proximal third to the middle third of the individually measured tibia length. The length of the Achilles tendon was measured on reconstructed isotropic images obtained by the MPRAGE sequence. The proximal point was defined as the last image before the appearance of the medial gastrocnemius head. The first image showing the AT attached to the calcaneus was defined as the distal point. This site is rarely involved in Achilles tendon rupture and can thus be measured in a ruptured, repaired or impaired tendon [31]. The number of slices between the distal and the proximal point was in turn the amount of millimetres the Achilles tendon travelled between the two points (slices of $1 \mathrm{~mm}$ ). The resulting length is thus the length of the Achilles tendon.

Semi-quantitative parameters were used to assess the degree of tendon morphology and tendon sheath fluid. The degree of tendon degeneration and tendon sheath fluid were

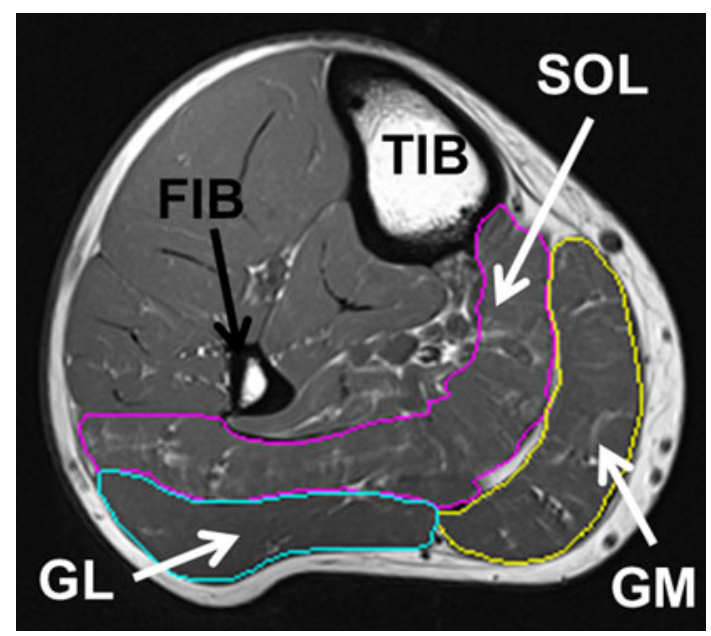

Fig. 3 Muscle volume measurement. The muscular areas of the gastrocnemius and soleus muscle were measured on each axial T1weighted fast spin-echo image. The area was multiplied by the sum of the slice thickness and the intersection gap in order to obtain the total muscle volume. SOL, soleus muscle; GM, gastrocnemius medialis muscle; GL, gastrocnemius lateralis muscle; TIB, tibia; FIB, fibula

determined according to Valderrabano et al. on a four-point grading scale (none/ $/$, mild/ + , moderate/ ++ , severe/ +++ ) on axial T2-weighted fat-saturated fast spin-echo images [34]. Fatty atrophy was defined as originally published on CT images and adapted to MR images for rotator cuff muscle integrity $[3,5]$. Radiological parameters were measured using the Santesoft DICOM Editor, Version 3.1.11, Athens, Greece.

\section{Statistical analysis}

The sample size was based on the precision of the volume measurements. Based on estimates of MV in three different treatment groups from the literature, an alpha of $5 \%$, a power of $80 \%$ and a minimum sample size of $n=43$ patients were required. Thus, after including $20 \%(n=9)$ to account for potential patient attrition or data loss, we included $n=43+9$, or $n=52$, healthy patients in this study. We used descriptive statistics including mean with standard deviation and frequencies to describe the populations, as appropriate. A one-way analysis of variance (ANOVA) with Bonferroni post hoc analysis was used to compare the parameters noted in Tables 1 and 2 except of skin palpation at the Achilles tendon, where a Chi-square test was used. For all comparisons, $R^{2}$ values were calculated in addition to the ANOVA $p$ values. For comparison of the affected with the healthy side, a paired $t$ test was used.

All reported tests were performed at the two-sided $5 \%$ significance level. All analyses were performed with IBM SPSS Statistics Version $20.0^{\circledR}$, IBM Corporation, Armonk, NY, USA. 


\section{Results}

\section{Clinical assessment}

For all treatment groups, days off work were not significantly different; even though it was striking that conservatively treated patients missed twice as many days of work as patients treated with open surgery (Table 1). When comparing surgically treated patients (open and percutaneous) with conservatively treated patients, no difference could be found (surgical, $48.3 \pm 47.9$ days (range 3-252); conservative, $75.4 \pm 177.9$ days (range 0-700), n.s.). Additionally, no disability pensions were paid out in any of the treatment groups.

In general, the clinical scores were good to excellent with only few outliers across the subgroups. The clinical scores showed good to excellent results without statistical significant difference (Table 1). Muscle volume correlated only to a small degree with the Hannover score but not with the ATRS or AOFAS hindfoot score (Table 3) as did fatty atrophy (Hannover, $R^{2}=0.03$, n.s.; ATRS, $R^{2}=0.04$, n.s.; AOFAS, $R^{2}=0.10, p=0.02$, respectively) showing little predictability of $\mathrm{MV}$ and fatty atrophy by clinical scores.

Maximum calf circumference (MCC) showed a significant difference between the affected and healthy leg (Table 1). Also, MCC was a good predictor of the degree of MV loss when the ratio of affected/healthy was evaluated $\left(R^{2}=0.37, p<0.0001\right)$. This was also true when looking at the absolute measures on the affected side and the healthy side (Table 3 ). The following algorithm gave a good estimate of the MV loss:

Muscle volume $\left(\mathrm{cm}^{3}\right)=35$

$\times$ maximum calf circumference $(\mathrm{cm})-566$

$\left(R^{2}=0.42, p<0.0001\right)$.

Adherent scars were seen to a higher degree (56\%) in patients treated percutaneously compared to $33 \%$ in the open surgery group $(p=0.01)$. No patient had irritations of the sural nerve.

In a subgroup analysis on gender differences, clinical values did not significantly differ (not depicted).

Table 1 Patient demographics and clinical outcomes

\begin{tabular}{|c|c|c|c|c|c|c|}
\hline & \multicolumn{6}{|c|}{ Treatment group } \\
\hline & $\begin{array}{l}\text { Open } \\
(n=21) \\
\text { Mean (SD) }\end{array}$ & $\begin{array}{l}\text { Percutaneous } \\
(n=16) \\
\text { Mean (SD) }\end{array}$ & $\begin{array}{l}\text { Conservative } \\
(n=15) \\
\text { Mean (SD) }\end{array}$ & $\begin{array}{l}\text { Total } \\
(n=52) \\
\text { Mean (SD) }\end{array}$ & $\begin{array}{l}\text { ANOVA } \\
p \text { value }\end{array}$ & $\begin{array}{l}t \text { test vs. } \\
\text { healthy } \\
p \text { value }\end{array}$ \\
\hline Follow-up (months) & $97.5(30.8)$ & $83.4(34.2)$ & $90.1(29)$ & $91(31.30)$ & n.s. & n.a. \\
\hline Age at follow-up (years) & $48.2(10.6)$ & $46.4(7.1)$ & $51.3(6.9)$ & $48.6(8.7)$ & n.s. & n.a. \\
\hline Age at injury (years) & $40.3(10.1)$ & $39.6(7.7)$ & $44.2(7.4)$ & $41.2(8.7)$ & n.s. & n.a. \\
\hline Days off work & $38(23)$ & $62(67)$ & $75(175)$ & $56(100)$ & n.s. & n.a. \\
\hline Height (cm) & $176.4(9.2)$ & $175.3(8)$ & $178.9(9)$ & $176.8(8.8)$ & n.s. & n.a. \\
\hline Weight (kg) & $82.1(13.7)$ & $78.1(13.8)$ & $86.2(9.8)$ & $82.1(12.9)$ & n.s. & n.a. \\
\hline BMI $\left(\mathrm{kg} / \mathrm{m}^{2}\right)$ & $26.4(4)$ & $25.3(3.2)$ & $27.1(4.3)$ & $26.2(3.9)$ & n.s. & n.a. \\
\hline AOFAS score & $97(5.9)$ & $93.2(7.7)$ & $93.4(8.3)$ & $94.8(7.3)$ & n.s. & n.a. \\
\hline ATRS score & $90.5(20.1)$ & $88.4(10.7)$ & $90.6(12.7)$ & $89.9(15.4)$ & n.s. & n.a. \\
\hline Hannover score & $86.7(6.8)$ & $80.2(12.2)$ & $79.1(11.9)$ & $82.5(10.6)$ & n.s. & n.a. \\
\hline Max.calf circumf. affected $(\mathrm{cm})$ & $38.1(3.4)$ & $37.7(3.1)$ & $37.7(3.7)$ & $37.9(3.3)$ & n.s. & $<0.0001$ \\
\hline Max.calf circumf. healthy $(\mathrm{cm})$ & $39.6(3.1)$ & $39.1(2.6)$ & $38.8(3.4)$ & $39.2(3)$ & n.s. & n.a. \\
\hline Max.calf circumf. \% & $0.96(0.04)$ & $0.96(0.03)$ & $0.97(0.03)$ & $0.97(0.03)$ & n.s. & n.a. \\
\hline $\begin{array}{l}\text { Thigh } 20 \mathrm{~cm} \text { above pat. affected } \\
(\mathrm{cm})\end{array}$ & $52.1(5.5)$ & $51.1(4.6)$ & $52.2(5.2)$ & $51.8(5.1)$ & n.s. & n.s. \\
\hline $\begin{array}{l}\text { Thigh } 20 \mathrm{~cm} \text { above pat. healthy } \\
(\mathrm{cm})\end{array}$ & $52.6(4.7)$ & $51.3(4.7)$ & $52.7(4.8)$ & $52.2(4.7)$ & n.s. & n.a. \\
\hline Thigh $20 \mathrm{~cm} \mathrm{\%}$ & $0.99(0.04)$ & $1(0.01)$ & $0.99(0.03)$ & $0.99(0.03)$ & n.s. & n.a. \\
\hline SF36 physical funct. functioning & $96.2(6.5)$ & $94.1(7.1)$ & $91.7(14.2)$ & $94.2(9.5)$ & n.s. & n.a. \\
\hline SF36 role physical & $22.6(6.7)$ & $25(0)$ & $22.9(5.7)$ & $23.4(5.3)$ & n.s. & n.a. \\
\hline SF36 bodily pain & $10.5(19.9)$ & $4.4(6.3)$ & $13.3(25.5)$ & $9.4(18.9)$ & n.s. & n.a. \\
\hline
\end{tabular}

$\%$ Percent of healthy side, SF36 short form 36, circumf circumference, ATRS Achilles tendon rupture score, AOFAS AOFAS hindfoot score, pat patella, * Chi square, n.a. not applicable, n.s not significant 
Table 2 MRI assessment

\begin{tabular}{|c|c|c|c|c|c|c|}
\hline & \multicolumn{6}{|l|}{ Treatment group } \\
\hline & $\begin{array}{l}\text { Open }(n=21) \\
\text { Mean }(\mathrm{SD})\end{array}$ & $\begin{array}{l}\text { Percutaneous }(n=16) \\
\text { Mean }(\mathrm{SD})\end{array}$ & $\begin{array}{l}\text { Conservative }(n=15) \\
\text { Mean }(\mathrm{SD})\end{array}$ & $\begin{array}{l}\text { Total }(n=52) \\
\text { Mean }(\mathrm{SD})\end{array}$ & $\begin{array}{l}\text { ANOVA } \\
p \text { value }\end{array}$ & $\begin{array}{l}t \text { test vs. healthy } \\
p \text { value }\end{array}$ \\
\hline \multicolumn{7}{|l|}{ Muscle volume } \\
\hline Total affected $\left(\mathrm{cm}^{3}\right)$ & $701.1(141.2)$ & $675.9(207.4)$ & $729.9(130.3)$ & $701.6(159.9)$ & n.s. & $<0.0001$ \\
\hline Total healthy $\left(\mathrm{cm}^{3}\right)$ & $853.7(164.8)$ & $863(183.8)$ & $833.6(121.4)$ & $850.8(157.4)$ & n.s. & n.a. \\
\hline Total \% & $0.82(0.07)$ & $0.79(0.17)$ & $0.88(0.11)$ & $0.83(0.12)$ & n.s. & n.a. \\
\hline \multicolumn{7}{|l|}{ Cross-sectional area } \\
\hline Total affected $\left(\mathrm{cm}^{2}\right)$ & $42.4(8.7)$ & $40.5(9.8)$ & $43.9(7.1)$ & $42.3(8.6)$ & n.s. & $<0.0001$ \\
\hline Total healthy $\left(\mathrm{cm}^{2}\right)$ & $46.8(12)$ & $44.8(11.8)$ & $45.8(6.5)$ & $45.9(10.5)$ & n.s. & n.a. \\
\hline Total \% & $0.94(0.22)$ & $0.94(0.25)$ & $0.96(0.08)$ & $0.94(0.2)$ & n.s. & n.a. \\
\hline \multicolumn{7}{|l|}{ Tendon } \\
\hline Morphology affected sheath & $0.38(0.59)$ & $0.5(0.63)$ & $0.43(0.51)$ & $0.43(0.57)$ & n.s. & n.s. \\
\hline Sheath fluid affected & $0.19(0.51)$ & $0.13(0.34)$ & $0.2(0.41)$ & $0.17(0.43)$ & n.s. & n.s. \\
\hline \multicolumn{7}{|l|}{ Achilles tendon length } \\
\hline Affected (mm) & $195.6(27)$ & $199.6(20)$ & $201.1(25)$ & $198.4(24)$ & n.s. & $<0.0001$ \\
\hline Healthy (mm) & $177.4(28)$ & $179.4(23)$ & $186.3(24)$ & $180.6(25)$ & n.s. & n.a. \\
\hline$\%$ & $1.11(0.09)$ & $1.12(0.08)$ & $1.08(0.08)$ & $1.1(0.08)$ & n.s. & n.a. \\
\hline
\end{tabular}

$\%$, Percent of healthy side; n.a., not applicable

\section{MRI assessment}

Significant MV loss of the affected leg compared to the matched, healthy leg was found across the three treatment subgroups (mean, $17 \%$ reduction). There was a $9.1 \%$ higher MV in the conservatively treated group as compared to the percutaneous treated group (Table 1). When comparing the operative groups (open and percutaneous together) with the conservative group, no difference could be found (n.s.). The subgroup analysis for the different muscles (SOL, GM, GL) did not show any significant differences. When looking at muscle atrophy as defined by fatty infiltration, the soleus and the gastrocnemius were significantly affected ( $p<0.0001$ and 0.006 , respectively). Analysis of the CSA revealed no significant difference in the treatment subgroups as well as the muscle subgroups (SOL, GM, GL).

The mean Achilles tendon was significantly longer in the affected leg when compared to the healthy leg (198.4 \pm 24.1 vs. $180.6 \pm 25.0 \mathrm{~mm}, p<0.0001)$ but not significantly different between treatment groups. In addition, there was no association between the type of treatment and MV (n.s.), CSA (n.s.), and degree fatty infiltration (n.s.).

Total MV of the healthy or affected side, respectively, did not correlate with the Achilles tendon length on the respective side. Clinically measured ankle dorsiflexion showed only a poor correlation with Achilles tendon length $\left(R^{2}=0.07, p=0.008\right)$, for this measurement, all legs and Achilles tendon lengths were evaluated $(n=104)$. The

Table 3 Predictors of muscle volume ( $R$ square)

\begin{tabular}{lllll}
\hline & \multicolumn{2}{l}{ Muscle volume } & & \\
\cline { 2 - 5 } & Affected side $(n=52)$ & Health side $(n=52)$ & Total $(n=104)$ & Ratio (affected/healthy) \\
\hline Cross-sectional area & $\mathbf{0 . 7 9}^{\mathrm{a}}$ & $\mathbf{0 . 4 9}^{\mathrm{a}}$ & $\mathbf{0 . 6 0}^{\mathrm{a}}$ & 0.0003 \\
Maximum calf circumference & $\mathbf{0 . 4 1}^{\mathrm{a}}$ & $\mathbf{0 . 3 8}^{\mathrm{a}}$ & $\mathbf{0 . 4 2}^{\mathrm{a}}$ & $\mathbf{0 . 3 7}^{\mathrm{a}}$ \\
Hannover & $\mathbf{0 . 0 8}^{\mathrm{a}}$ & & \\
ATRS & $0.049^{\mathrm{a}}$ & & & \\
AOFAS & $0.001^{\mathrm{a}}$ & & \\
\hline
\end{tabular}

Depicted are $R^{2}$ values

Hannover, Hannover Achilles tendon score; ATRS, Achilles tendon rupture score; AOFAS, American Orthopaedic Foot and Ankle Society Hindfoot score; total, $n=104$

a Significant 
same weak correlation was found for the affected $\left(R^{2}=0.14, p=0.006\right)$ and the healthy side $\left(R^{2}=0.01\right.$, n.s.) separately. Clinically measured passive dorsiflexion measurements did not show a difference between the treatment groups (open, $19.7^{\circ} \pm 3.2^{\circ}$; percutaneous, $19.9^{\circ} \pm 3.6^{\circ}$; conservative, $19.8^{\circ} \pm 6.7^{\circ}$; n.s.). In addition, the affected $\left(19.8^{\circ} \pm 4.5^{\circ}\right)$ and the healthy side $\left(18.4^{\circ} \pm 5.7^{\circ}\right)$ did not show a significant difference (n.s.). As expected, MV correlated with CSA (Table 3).

\section{Discussion}

This study focused on functional and imaging outcomes after Achilles tendon treatment with comparison of the three treatment mainstreams (open repair, percutaneous suture and non-operative treatment). No significant differences in MRI and clinical scores outcomes were found between the three treatment groups.

Controversy remains as to which treatment algorithm is best followed for acute Achilles tendon rupture. However, there is consensus that open reconstruction is best suitable for athletes [1]. Whichever treatment is chosen, sequelae from surgical site infections, scar adhesions and sural nerve irritation in operative techniques [37], higher re-rupture rates in conservative treatment [10] and deep vein thrombosis, muscle atrophy $[6,13,25]$, days off work and loss of function for all treatments exist [25].

Muscle atrophy as a potential consequence of Achilles tendon ruptures has not been correlated with Achilles tendon length. These measurements were now performed on treated and healthy tendons and we found them to be healed in over length with a mean of $110 \%$ compared to the healthy side showing that original tendon length cannot be restored independent of the type of treatment. Until now, Achilles tendon length was measured by implanting metal markers into the tendon and looking at the gapping or increase in ankle dorsiflexion in different post-operative rehabilitation protocols without measuring the actual Achilles tendon length, thus lacking direct comparison to our findings [8, 21, 22]. In a previous study, we evaluated Achilles tendon length [27] and showed that dorsiflexion of the ankle joint, although significant, is only a weak predictor $\left(R^{2}=0.07\right)$ of Achilles tendon length and should thus not be used to assess Achilles tendon overlength after repairs $[12,21]$.

Muscle volume was found to be diminished in all treatment groups. Although open surgery is intended to result in better anatomic reconstruction, we found a MV loss of $18 \%$ in the open surgery group. To our knowledge, MV of the posterior calf has never been measured in an accurate manner. When looking at fatty infiltration as an indicator of muscle atrophy, there was no significant difference between the treatment groups either. Nevertheless, fatty atrophy was still present after more than 7.5 years of follow-up. With the supraspinatus muscle, it is already known that muscle atrophy does not completely reverse [15]. We can support this finding by looking at the posterior calf muscles. A recent study of Olsson et al. [24] revealed that major functional deficits persist even 2 years after Achilles tendon rupture and that patients do not improve significantly between 1 and 2 years after the rupture. Rebeccato et al. retrospectively compared 52 tendon ruptures with a minimal follow-up of 12 months. The results revealed a loss of posterior muscle compartment area of $18 \%$ in the open group, $19 \%$ with Ma-Griffith and $9 \%$ in Kakiuchi repair group, respectively. While Haggmark et al. [6] compared 15 non-operatively with 8 surgically treated patients and showed a significant reduction in calf muscle area (no follow-up stated), Leppilahti et al. [13] showed calf muscle atrophy of $15 \%$ on the affected leg in the analysis of CSA by means of CT scans (mean 3.1 years follow-up). In our findings, the CSA was higher after more than 7.5 years of follow-up although not significantly different. This might be due to the fact that patients might recover to a high degree even between 2.9 years (Rebeccato et al.) and 7.5 years (our cohort) of follow-up. The affected muscles and tendons might recover after such a long follow-up. Another fact that supports the recovery theory is the circumstance that we saw a reduction in MCC of $-1.3 \mathrm{~cm}$ which was noted to be $-2.55 \mathrm{~cm}$ in the study of Rebeccato et al. [25].

Although days off work did not significantly differ throughout the treatment groups, it was notable that there were almost twice as many days missed in conservative treatment compared to open surgery, though this might be due to the large standard deviation in the conservatively treated group. This should be considered when cost effectiveness of treatments is discussed. While conservative treatment might be cheaper in direct treatment costs, total societal cost might be equivalent if patients return to work consistently earlier after open treatment. Percutaneous treatment was situated in between the two. When compared to other studies, days off work have been reported to be in the same range $[18,25]$.

All clinical scores showed good to excellent results. These results were consistent with the literature stating the same ranges even after shorter follow-up periods [9, 30]. Although clinical scores might be a good measure for short- to mid-term outcome, it appeared that the discrimination of results in a long-term follow-up become more difficult in the very good to excellent range. The fact of less muscle atrophy in our long-term follow-up did not add to a better outcome by means of clinical scores.

Of great clinical interest might be two parameters: CSA and MCC both showing strong correlations with MV 
(Table 3). The strong correlation between MV and CSA will make it easy to approximate MV by simple measurements on ultrasonography and replace the costly and timeconsuming MRI measurements. This supports other studies, which have used the CSA for the approximation of calf MV [6, 13, 19, 25]. Even less costly is the clinical measurement of maximum calf circumference. In contrast to Haggmark et al., who showed a poor correlation, we found a strong correlation of cross-sectional area with muscle volume. This could be due to the fact that Haggmark only measured the CSA and not the MV of the whole posterior calf, giving less accurate results. When looking at correlations between CSA and maximum calf circumference, the latter seemed to be a good predictor of CSA on the affected side as well as for the healthy side.

Strengths of this study were the strict in- and exclusion criteria as well as the long follow-up time of 91 months. Radiologists and radiology assistants were blinded for the study. Additionally, the orthopaedic surgeon performing the follow-up measurements was independent and did not treat the patients before or after the study. For the first time in the literature, MV was measured for the triceps surae and correlated to cross-sectional area, Achilles tendon length and clinical parameters. Fatty atrophy grading according to Goutallier was introduced into calf muscles [5].

There were certain limitations to this study. Firstly, there might be a selection bias and patients that did not have a good outcome might not consent to be followed up. We tried to overcome this burden by contacting all consecutive patients from the database in the years stated in Fig. 1. Operative indications and treatment across centres in a multicentre setup might differ considerably making the operative groups heterogeneous. Additionally, some patients were lost due to the time-consuming examinations at different sites.

\section{Conclusions}

No significant difference between the treatment groups was found by means of clinical scores, days off work, clinical measurements, ATL, MV after more than 7.5 years of follow-up. No general recommendation can be given on the generally best treatment option even after examining consecutive patients. Ultrasonography and MCC are easy and cost-effective measurements and a very good approximation of MV of the posterior calf even in the untreated limb and can thus be used in daily clinical work.

Acknowledgments We thank Tanja Haas for her MRI examinations. We thank Professor Beat Hintermann and Dr. Martin Majewski, for their contribution in patient acquisition. The lead centre of this study was the University Hospital Basel, Basel, Switzerland. This multicentre study was funded by a grant from the Swiss National Accident Insurance Company (SUVA), Lucerne, Switzerland. Each author certifies that his or her institution has approved the human protocol for this investigation that all investigations were conducted in conformity with ethical principles of research and that informed consent for participation in the study was obtained.

Conflict of interest Each author additionally certifies that he or she has no commercial associations that might pose a conflict of interest in connection with the submitted article. The authors indicate that they have no conflict of interest.

\section{References}

1. Cetti R, Christensen S, Ejsted R, Jensen N, Jorgensen U (1993) Operative versus nonoperative treatment of Achilles tendon rupture. A prospective randomized study and review of the literature. Am J Sports Med 21(6):791-799

2. Gerber C, Schneeberger A, Hoppeler H, Meyer D (2007) Correlation of atrophy and fatty infiltration on strength and integrity of rotator cuff repairs: a study in thirteen patients. J Shoulder Elbow Surg 16(6):691-696

3. Gerber C, Schneeberger AG, Hoppeler H, Meyer DC (2007) Correlation of atrophy and fatty infiltration on strength and integrity of rotator cuff repairs: a study in thirteen patients. J Shoulder Elbow Surg 16(6):691-696

4. Gladstone JN, Bishop JY, Lo IK, Flatow EL (2007) Fatty infiltration and atrophy of the rotator cuff do not improve after rotator cuff repair and correlate with poor functional outcome. Am J Sports Med 35(5):719-728

5. Goutallier D, Postel JM, Bernageau J, Lavau L, Voisin MC (1994) Fatty muscle degeneration in cuff ruptures. Pre- and postoperative evaluation by CT scan. Clin Orthop Relat Res 304:78-83

6. Häggmark T, Liedberg H, Eriksson E, Wredmark T (1986) Calf muscle atrophy and muscle function after non-operative vs operative treatment of achilles tendon ruptures. Orthopedics 9(2):160-164

7. Kakiuchi M (1995) A combined open and percutaneous technique for repair of tendo Achillis. Comparison with open repair. J Bone Joint Surg Br 77(1):60-63

8. Kangas J, Pajala A, Ohtonen P, Leppilahti J (2007) Achilles tendon elongation after rupture repair: a randomized comparison of 2 postoperative regimens. Am J Sports Med 35(1):59-64

9. Kearney RS, Achten J, Lamb SE, Plant C, Costa ML (2012) A systematic review of patient-reported outcome measures used to assess Achilles tendon rupture management: what's being used and should we be using it? Br J Sports Med 46(16):1102-1109

10. Khan R, Fick D, Keogh A, Crawford J, Brammar T, Parker M (2005) Treatment of acute achilles tendon ruptures. A metaanalysis of randomized, controlled trials. J Bone Joint Surg Am 87(10):2202-2210

11. Kitaoka HB, Alexander IJ, Adelaar RS, Nunley JA, Myerson MS, Sanders M (1994) Clinical rating systems for the ankle-hindfoot, midfoot, hallux, and lesser toes. Foot Ankle Int 15(7):349-353

12. Leppilahti J, Forsman K, Puranen J, Orava S (1998) Outcome and prognostic factors of achilles rupture repair using a new scoring method. Clin Orthop Relat Res 346:152-161

13. Leppilahti J, Lähde S, Forsman K, Kangas J, Kauranen K, Orava S (2000) Relationship between calf muscle size and strength after achilles rupture repair. Foot Ankle Int 21(4):330-335 
14. Leppilahti J, Siira P, Vanharanta H, Orava S (1996) Isokinetic evaluation of calf muscle performance after Achilles rupture repair. Int J Sports Med 17(8):619-623

15. Liem D, Lichtenberg S, Magosch P, Habermeyer P (2007) Magnetic resonance imaging of arthroscopic supraspinatus tendon repair. J Bone Joint Surg Am 89(8):1770-1776

16. Ma G, Griffith T (1977) Percutaneous repair of acute closed ruptured achilles tendon: a new technique. Clin Orthop Relat Res 128:247-255

17. Maffulli N, Longo UG, Maffulli GD, Khanna A, Denaro V (2011) Achilles tendon ruptures in elite athletes. Foot Ankle Int 32(1):9-15

18. Majewski M, Schaeren S, Kohlhaas U, Ochsner PE (2008) Postoperative rehabilitation after percutaneous Achilles tendon repair: early functional therapy versus cast immobilization. Disabil Rehabil 30(20-22):1726-1732

19. Maughan RJ, Watson JS, Weir J (1984) Muscle strength and cross-sectional area in man: a comparison of strength-trained and untrained subjects. Brit J Sports Med 18(3):149-157

20. Möller M, Movin T, Granhed H, Lind K, Faxén E, Karlsson J (2001) Acute rupture of tendon Achillis. A prospective randomised study of comparison between surgical and non-surgical treatment. J Bone Joint Surg Br 83(6):843-848

21. Mortensen H, Skov O, Jensen P (1999) Early motion of the ankle after operative treatment of a rupture of the Achilles tendon. A prospective, randomized clinical and radiographic study. J Bone Joint Surg Am 81(7):983-990

22. Mullaney MJ, McHugh MP, Tyler TF, Nicholas SJ, Lee SJ (2006) Weakness in end-range plantar flexion after Achilles tendon repair. Am J Sports Med 34(7):1120-1125

23. Nilsson-Helander K, Thomeé R, Grävare-Silbernagel K, Thomeé P, Faxén E, Eriksson B, Karlsson J (2007) The Achilles tendon Total Rupture Score (ATRS): development and validation. Am J Sports Med 35(3):421-426

24. Olsson N, Nilsson-Helander K, Karlsson J, Eriksson BI, Thomee R, Faxen E, Silbernagel KG (2011) Major functional deficits persist 2 years after acute Achilles tendon rupture. Knee Surg Sports Traumatol Arthrosc 19(8):1385-1393

25. Rebeccato A, Santini S, Salmaso G, Nogarin L (2001) Repair of the achilles tendon rupture: a functional comparison of three surgical techniques. J Foot Ankle Surg 40(4):188-194
26. Rettig AC, Liotta FJ, Klootwyk TE, Porter DA, Mieling P (2005) Potential risk of rerupture in primary achilles tendon repair in athletes younger than 30 years of age. Am J Sports Med 33(1):119-123

27. Rosso C, Schuetz P, Polzer C, Weisskopf L, Studler U, Valderrabano V (2012) Physiological achilles tendon length and its relation to tibia length. Clin J Sport Med 22(6):483-487

28. Sadoghi P, Rosso C, Valderrabano V, Leithner A, Vavken P (2012) Initial Achilles tendon repair strength-synthesized biomechanical data from 196 cadaver repairs. Int Orthop 36(9):1947-1951

29. Sadoghi P, Rosso C, Valderrabano V, Leithner A, Vavken P (2013) The role of platelets in the treatment of Achilles tendon injuries. J Orthop Res 31(1):111-118

30. Sarzaeem MM, Lemraski MM, Safdari F (2012) Chronic Achilles tendon rupture reconstruction using a free semitendinosus tendon graft transfer. Knee Surg Sports Traumatol Arthrosc 20(7):13861391

31. Speck M, Klaue K (1998) Early full weightbearing and functional treatment after surgical repair of acute achilles tendon rupture. Am J Sports Med 26(6):789-793

32. Tadokoro K, Matsui N, Yagi M, Kuroda R, Kurosaka M, Yoshiya S (2004) Evaluation of hamstring strength and tendon regrowth after harvesting for anterior cruciate ligament reconstruction. Am J Sports Med 32(7):1644-1650

33. Thermann H, Zwipp H, Tscherne H (1995) Functional treatment concept of acute rupture of the Achilles tendon. 2 years results of a prospective randomized study. Unfallchirurg 98(1):21-32

34. Valderrabano V, Hintermann B, Wischer T, Fuhr P, Dick W (2004) Recovery of the posterior tibial muscle after late reconstruction following tendon rupture. Foot Ankle Int 25(2):85-95

35. Valderrabano V, Pagenstert G, Horisberger M, Knupp M, Hintermann B (2006) Sports and recreation activity of ankle arthritis patients before and after total ankle replacement. Am J Sports Med 34(6):993-999

36. Weber M, Niemann M, Lanz R, Muller T (2003) Nonoperative treatment of acute rupture of the achilles tendon: results of a new protocol and comparison with operative treatment. Am J Sports Med 31(5):685-691

37. Young JS, Kumta SM, Maffulli N (2005) Achilles tendon rupture and tendinopathy: management of complications. Foot Ankle Clin 10(2):371-382 